\title{
A System Analysis of the Enthalpy Change in the Absorber Section of the Ammonia Absorption Refrigerator.
}

\author{
Satyendra Sunkavally ${ }^{\# 1}$, Muzeer Shaik ${ }^{* 2}$ \\ \# Assistant Professor, Department of Mechanical Engineering V.R. Siddhartha Engineering College \\ Vijayawada-7,India. \\ * M.Tech II Year, Department of Mechanical Engineering V.R. Siddhartha Engineering College Vijayawada-7, \\ India.
}

\begin{abstract}
The ammonia absorption refrigerator is a cost effective means of refrigeration that is particularly relevant to indigent tropical and sub-tropical nations[6]. An energy audit of the various enthalpy changes that occur in the various components of this system is here with conducted using real time data, typical operational temperatures and pressures with a view to establishing the relationship between the predicted theoretical heat release in the absorber section of this refrigerator and the actual observed heat release in the absorber. Such analysis reveals a most remarkable discrepancy between the theoretical enthalpy and the empirically determined enthalpy, amounting to as much as 50\% above the predicted heat release (6.16078 KW vs. 11.617 $K W)$. Various possible molecular mechanisms that might account for this "energy gap " are briefly discussed.
\end{abstract}

Keywords: Absorber Section Enthalpy, Ammonia Absorption Absorber Analysis. Missing amount of enthalpy in absorber.

\section{Introduction}

The ammonia absorption refrigerator has established itself as a rugged and reliable means of refrigeration that is particularly suitable for the impoverished nations of tropical Asia and Africa. The fact that it does not employ a compressor for vapor compression, as do vapor compression refrigerators, drastically reduces its cost and brings it within the affordability range of indigent denizens. The reason for this is that the compressor is the most expensive part of a refrigerator.

The ammonia absorption refrigerator was invented by the French man Lande' in 1873. Its primary use now is in the industrial and the mass refrigeration sector of the food industry. A suitable low cost version appropriate for domestic use has not yet been designed for mass production, a regrettable lacuna given its potentially low cost and ready affordability[1],[2].

\section{Mechanism Of Operation}

The vapor absorption system, like the vapor compression system employs a volatile refrigerant to absorb the heat, but differs from the latte in the means employed to circulate the refrigerant, by maintaining a pressure difference. In the VCS, a compressor is used, while in the VAS, an absorber and a generator are used. Since the generator is often driven by waste heat there is a considerable saving in electricity.

The VAS is composed of two basic segments: a low pressure side composed of the evaporator and absorber and a high pressure side composed of the generator and condenser.

Beginning from the high pressure side, the liquid refrigerant coming out from the condenser is at too high a pressure (necessarily so for the condensation process from vapor to liquid to occur), and since the boiling point at this high pressure is too great to be useful for regeneration purposes the pressure must be reduced. This is accomplished by passing the liquid through an expansion valve that reduces the pressure sufficiently low that the boiling point falls to the temperature required in the refrigerated space. The liquid now passes into the evaporator where it absorbs the latent heat of vaporization from the material in kept in the refrigerated space whose temperature we wish to keep at a low level. The low pressure vapor then passes into the absorber where the ammonia is absorbed by the liquid releasing its latent heat of condensation. The key point to be noted is that the vapor moves from the evaporator into the absorber because the vapor pressure of the absorbent-refrigerant solution is greater than that of the vapor pressure in the evaporator of the pure liquid ammonia. The absorber binary solution thus is the primary determinant of the vapor pressure prevailing I the evaporator, and since evaporation temperature is determined by pressure ( the lower the pressure the lower the boiling point and the colder then can the refrigerated space be held), the absorber solution controls the setpoint temperature. The colder the solution (and it will be if the heat released in it is promptly removed by a cool external liquid) and the less concentrated it is with the refrigerant, the lower will be its vapor pressure, and thus the colder the refrigerated space can be. Condensation of the ammonia from vapor to liquid in the absorber involves a massive (1000-fold) reduction in volume which is tantamount to compression. 
As more and more ammonia vapor condenses into the absorbent solution, the concentration of the ammonia in this solution will rise, which will tend to raise the vapor pressure, thereby resulting in a rise of the set-point temperature in the refrigerated space. This obviously is not desirable and to ensure set-point preservation the highly concentrated solution must be continuously replenished by low-concentrated solution.

This is accomplished by pumping this concentrated solution to a structure called a generator, where external heat is used to drive the more volatile ammonia out of solution into the space above the generator. The pump must accomplish two tasks 1) that of solution transfer and 2) that of raising the pressure of this solution. The reason is that this will then allow the vapor to be driven off at high pressure as well, which will facilitate its condensation in the condenser downstream. The pump does not have to do much work since the solution is basically an incompressible fluid.

The solution in the generator upon losing its ammonia then becomes the desired low-concentration solution which is then sent back to the absorber to capture more ammonia vapor coming from the evaporator, after first passing through a valve that reduces its pressure to that prevailing in the absorber. The high pressure ammonia vapor coming out of the generator - which is composed predominantly of ammonia vapor, with a miniscule admixture of water vapor, since ammonia is more volatile than water then condenses to liquid in the condenser, a liquid that is almost all pure ammonia.

The high pressure liquid ammonia coming out of the condenser then has its pressure reduced by passage through an expansion valve, and is then sent to the evaporator, where the cycle repeats itself all over again[5].

The important point to note is that the set-point temperature in the in the refrigerated space is determined by, as aforementioned, by both the ammonia concentration in the ammonia-water solution in the absorber and the temperature of this solution itself. The lower these two parameters the lower can be the setpoint temperature. Little control can be exerted on the temperature of the solution, since this is determined by the availability of an external cooling liquid whose normal temperature, while necessarily lower than the absorbent solution, is controlled by climatic factors. Thus in VAS the primary control is exerted on the concentration of the ammonia-water absorbent solution in the absorber. This is accomplished by controlling the heat supply to the generator. The more the heat supplied the more the ammonia vapor driven off there and the more dilute in ammonia is the solution returned to the absorber from the generator. A highly dilute solution in the absorber will then have a lower vapor pressure of ammonia and thus will induce a correspondingly low vapor pressure in the evaporator, and this reduced in $\mathrm{P}_{\text {sat }}$ will allow a lower $\mathrm{T}_{\text {sat }}$, that is a lower set-point temperature.

A general schematic of the various components that comprise the AARS and their consectaneous connections is given below along with typical operational pressures and temperatures:

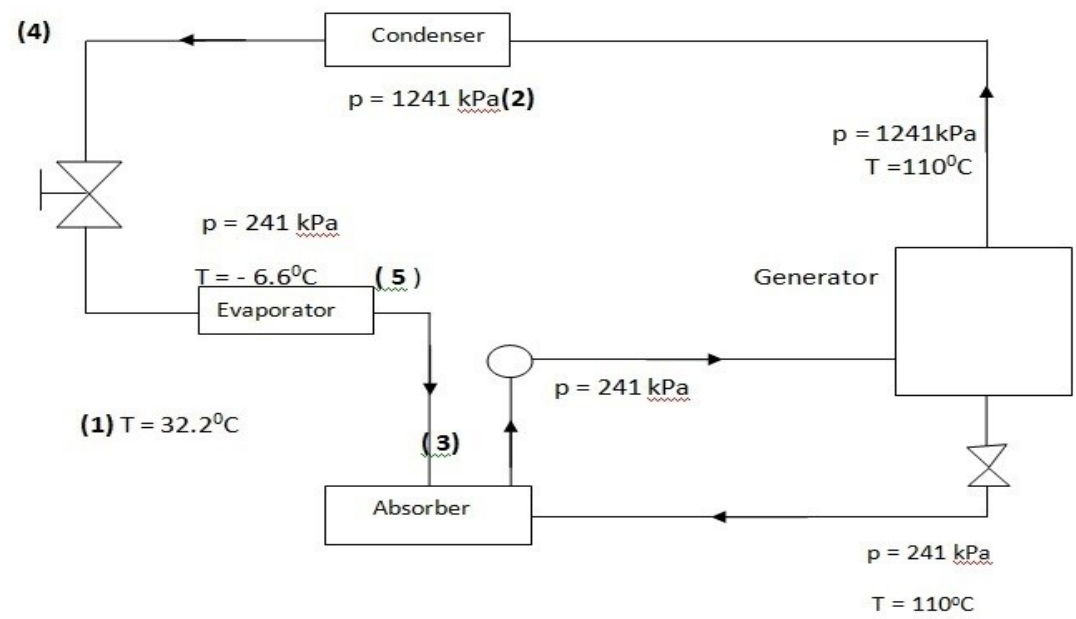

Fig.1 The schematic diagram of ammonia vapor refrigeration system.

The following series of calculations can then be done to determine heat release[3],[4].

$$
\begin{aligned}
& 1 ; \quad \mathrm{T}=32.2^{0} \mathrm{C}, \mathrm{p}=241 \mathrm{kPa}, \\
& \mathrm{x}=0.40, \mathrm{~h}_{\mathrm{L}}=-116 \mathrm{KJ} / \mathrm{Kg} \\
& 2 . \quad \mathrm{T}=110{ }^{0} \mathrm{C}, \mathrm{p}=1241 \mathrm{kPa}, \\
& \mathrm{x}^{\prime},=0.910, \mathrm{~h}_{\mathrm{V}=1590 \mathrm{KJ} / \mathrm{kg}} \\
& 3 . \quad \mathrm{T}=110{ }^{0} \mathrm{C}, \mathrm{p}=1241 \mathrm{kPa}, \\
& \mathrm{x}^{\prime}=0.30, \mathrm{~h}_{\mathrm{L}}=250 \mathrm{KJ} / \mathrm{kg}
\end{aligned}
$$


4. $\mathrm{P}=1241 \mathrm{kPa}, \mathrm{x}_{4},=\mathrm{x}_{2},=0.910$

5. $\mathrm{T}=-6.6^{0} \mathrm{C}, \mathrm{p}=241 \mathrm{kPa}$.

At point 5 the mixture is a combination of $91 \%$ ammonia vapor and $9 \%$ water because $\mathrm{x}_{2}, \mathrm{x}_{4},=\mathrm{x}_{5}$ (composite dryness fraction)

Both the liquid and the ammonia vapor are contaminated at point 5 . The water contains some ammonia and the ammonia vapor contains some water. These masses therefore have to be calculated individually.

At point $5, \mathrm{p}=241 \mathrm{kPa}, \mathrm{T}=-6.6^{0} \mathrm{C}$.

Thus from table $\mathrm{b} 3$ we find that $\mathrm{x}_{5},=0.760$,

$\mathrm{h}_{\mathrm{L}}=-218 \mathrm{KJ} / \mathrm{Kg}$. for the ammonia vapor at $\mathrm{p}=241 \mathrm{kPa}$ and $\mathrm{T}=-6.6^{0} \mathrm{C}, \mathrm{x}_{5}{ }^{,}=0.999^{+}, \mathrm{h}_{\mathrm{V}}=1260 \mathrm{KJ} / \mathrm{Kg}$.

using the mass balance equation

$$
\begin{gathered}
1\left(\mathrm{x}_{5}\right)=\mathrm{m}_{\mathrm{pl}} \cdot \mathrm{x}_{5},+\left(1-\mathrm{m}_{\mathrm{pl}}\right) \mathrm{x}_{5}, . \\
1(0.910)=\mathrm{m}_{\mathrm{pl}}(0.760)+\left(1-\mathrm{m}_{\mathrm{pl}}\right)(0.999) \\
0.239 \mathrm{~m}_{\mathrm{pl}}=0.089 \\
\mathrm{~m}_{\mathrm{pl}}=0.372 \mathrm{Kg} . \\
\text { thus, } \mathrm{h}_{5}=0.372(-218)+(1-0.372)(1260)-81.096+791.28=710.184 \mathrm{KJ} / \mathrm{kg} .
\end{gathered}
$$

Now assuming 1 ton of refrigeration is required, we have :

$\mathrm{m}_{2}=\mathrm{m}_{4}=\mathrm{m}_{5}$ (since we are referring to the entire mass of the mixture, i.e both the purge liquid and the water contaminated ammonia vapor.

$$
\begin{aligned}
\mathrm{m}_{2}= & 3.516 \mathrm{KW} \text { per ton } /\left(\mathrm{h}_{5}-\mathrm{h}_{4}\right) \\
= & 3.516 /(710.184-250) \\
& =7.640 \times 10^{-3} \mathrm{Kg} / \mathrm{sec} .
\end{aligned}
$$

$\mathrm{m}_{1}$ and $\mathrm{m}_{3}$ still needs to be determined, where $\mathrm{m}_{1}$ is equal to the mass of the liquid going from the absorber to the generator; and $\mathrm{m}_{3}$ is the liquid going from the generator back to the absorber after the ammonia has been mostly removed from it.

$\mathrm{m}_{1}$ and $\mathrm{m}_{3}$ can be found from two simultaneous equations:

1) Total mass balance: $m_{1}=m_{2}+m_{3}$

2) Ammonia balance: $\mathrm{m}_{1} \mathrm{x}_{1}=\mathrm{m}_{2} \mathrm{x}_{2}+\mathrm{m}_{3} \mathrm{x}_{3}=0.40$

$$
\begin{aligned}
\mathrm{m}_{1}=0.910 \mathrm{~m}_{2} & +0.05 \mathrm{~m}_{3} . \\
\text { Thus } \mathrm{m}_{1}-\mathrm{m}_{3}=\mathrm{m}_{2} & =7.640 \times 10^{-3} \\
& =0.007640 \ldots \ldots \ldots \ldots \\
0.40 \mathrm{~m}_{1}-0.05 \mathrm{~m}_{3} & =0.910 \mathrm{~m}_{2} \\
& =0.910 \times 7.640 \times 10^{-3} \\
& =0.0069524 \ldots \ldots \ldots \ldots
\end{aligned}
$$

Multiplying equation(1) throughout by 0.40 , we have

$$
\begin{array}{r}
0.40 \mathrm{~m}_{1}-0.40 \mathrm{~m}_{3}=7.640 \times 10^{-3} \times 0.40 \\
=3.056 \times 10^{-3} \ldots
\end{array}
$$

Subtracting equation (3) from equation (2), we have:

$$
\begin{gathered}
0.35 \mathrm{~m}_{3}=0.003896 \\
\text { Thus, } \mathrm{m}_{3}=0.0111 \mathrm{~kg} / \mathrm{sec} .
\end{gathered}
$$

Substituting this value of $\mathrm{m}_{3}$ in equation (1), we have

$$
\mathrm{m}_{1}=0.007640+0.0111=0.01874 \mathrm{~kg} / \mathrm{sec} .
$$

The heat released in the absorber, $\mathrm{Q}_{\mathrm{A}}$, can be determined by conducting an energy audit on the absorber. The governing equation is

$$
\mathrm{Q}_{\mathrm{A}}+\mathrm{m}_{1} \mathrm{~h}_{1}=\mathrm{m}_{3} \mathrm{~h}_{3}+\mathrm{m}_{5} \mathrm{~h}_{5}
$$

Using table $\mathrm{b} 3$ for point 1 at condition $\mathrm{p}=241 \mathrm{kPa}$ and $\mathrm{T}=32.2^{\circ} \mathrm{C}$, we find $\mathrm{h}_{\mathrm{L}}=-116 \mathrm{KJ} / \mathrm{Kg}$. Similarly for point 3 at $\mathrm{p}=241 \mathrm{kPa}$, and $\mathrm{T}=110^{\circ} \mathrm{C}$ we have $\mathrm{h}_{3}=362 \mathrm{KJ} / \mathrm{Kg}$.

Thus, substituting these values of $\mathrm{m}_{1}, \mathrm{~m}_{2}, \mathrm{~m}_{3}, \mathrm{~h}_{1}, \mathrm{~h}_{2}$, and $\mathrm{h}_{3}$ in equation(4), we have 


$$
\begin{gathered}
\mathrm{Q}_{\mathrm{A}}=(0.01874 \times 116)+(0.0111 \times 362) \\
+(0.007640 \times 710.184) \\
=2.17384+4.0182+5.4258 \\
=11.617 \mathrm{KJ} / \mathrm{sec} .
\end{gathered}
$$

This is the amount of heat released per second in the absorber.

Now using ammonia tables we find that at $-6.6^{\circ} \mathrm{C}$ the heat released as latent heat of condensation by the saturated ammonia vapor $=\mathrm{h}_{\mathrm{fg}}=1285.34 \mathrm{KJ} / \mathrm{Kg}$ of ammonia vapor.

Now at point 5 for every one $\mathrm{kg}$ of mixture, there is (1-0.372) $\mathrm{kg}$ of water contaminated ammonia. Thus the total amount of pure ammonia vapor in this contaminated ammonia $=[(1-0.372) \times 0.999] \mathrm{kg}$. Thus in $0.007640 \mathrm{~kg}$ of mixture at point 5 , the amount of pure ammonia vapor alone that needs to be condensed releasing its latent heat of condensation is :

$[(1-0.372) \times 0.999] \times 0.007640=4.79312 \times 10^{-3} \mathrm{~kg}$ of pure ammonia vapor per second.

Thus the latent heat of condensation released is equal to $4.79312 \times 10^{-3} \times 1285.34 \mathrm{KJ} / \mathrm{sec}=6.16078 \mathrm{KJ} / \mathrm{sec}$. Thus we see that the latent heat of condensation does not fully account for the heat released in the absorber which is equal to $11.617 \mathrm{KJ} / \mathrm{sec}$.

There is a " missing amount " of energy equal to $11.617-6.16078=\mathbf{5 . 4 5 6 2 2} \mathbf{~ K J} / \mathbf{s e c}$ that remain unaccounted for.

\section{Conclusion}

An energy audit of the ammonia absorption system reveals an utterly unexpected and remarkable lacuna. An excess energy amounting to nearly $50 \%$ over and above the latent heat of condensation has been uncovered. A discrepancy of this magnitude demands explanation. In molecular terms it is difficult to envision a mechanism capable of a heat genesis of this magnitude. Some possible candidates are as follows:

1) It is known that when ammonia, a base, goes into solution, it partially combines with water to generate the ammonium ion and the hydroxyl ion. While anions such as the hydroxyl ion have a poor capacity in general to attract water and form shells of hydration, the reverse is true for cations such as the ammonium ion that form extensive shells of hydration, releasing heat energy as the heat of hydration [8].

2) Another possible contributor might be the release of the potential energies of the orientation potential, the induction potential and the dispersion potential[7]. The absorption of ammonia into water by allowing better intermolecular packing may allow the ammonia molecules to approach far closer to each other than would be the case if pure ammonia vapor were condensing. This would allow the discharge of a far greater amount of potential energy as heat energy. Furthermore the higher efficiency of this packaging would imply that the intermolecular distance between water and ammonia molecules would also decrease further contributing to such heat release. The fact that at STP 1130 liters of ammonia are solvated in one liter of water would suggest such enhanced, more dense packing.

In two subsequent papers, the relative magnitudes of these energy releases will be calculated and their potential contributions to the excess heat genesis in the absorber will be examined in detail.

\section{References}

[1] Cengel ${ }^{\text {a }}$, Y.A. and Boles, M.A. (2011) Thermodynamics - an engineering approach (7 ${ }^{\text {th }}$ edition), McGraw-Hill Companies, Inc, NY. Pages: $305-306$

[2] Cengel ${ }^{\text {b }}$, Y.A. and Boles, M.A. (2011) Thermodynamics - an engineering approach (7 ${ }^{\text {th }}$ edition), McGraw-Hill Companies, Inc, NY. Pages: 633-635.

[3] Burghhardt ${ }^{\text {a }}$, M.D. (1982) Engineering Thermodynamics with applications (2 ${ }^{\text {nd }}$ edition). Pages: 259-267.

[4] Burghhardt ${ }^{\text {b }}$ M.D. (1982) Engineering Thermodynamics with applications ( $2^{\text {nd }}$ edition). Page: 547.

[5] Dossat, R.J.(1997) Principles of Refrigeration(4 ${ }^{\text {th }}$ edition), Pearson Education, Inc. Pages: 469-472

[6] Nag, P.K. (2008). EngineeringThermodynamics( $4^{\text {th }}$ edition), Tata McGraw-Hill Education Private Limited. Pages: 580

[7] Moore, W.J. (1972 ). Physical Chemistry( $5^{\text {th }}$ edition). Orient Longman Private Limited. Pages: 913 - 915.

[8] Petrucci, R.H. (1989) General Chemistry ( $5^{\text {th }}$ edition) McMillan Publishing Company, New York. Pages: $792-793$. 